\title{
Erratum to: Peristaltic flow of a nanofluid in a non-uniform tube
}

\author{
Noreen Sher Akbar $\cdot$ S. Nadeem - T. Hayat • \\ Awatif A. Hendi
}

Published online: 1 November 2011

(C) Springer-Verlag 2011

Erratum to: Heat and Mass Transfer

DOI 10.1007/s00231-011-0892-7

In the above mentioned article, in Eq. (11) the following terms of $N_{b}$ and $N_{t}$ have been considered as follows:

$N_{b}=\frac{(\rho c)_{p} D_{B} \bar{C}_{0}}{(\rho c)_{f} \alpha}, \quad N_{t}=\frac{(\rho c)_{p} D_{\bar{T}}}{(\rho c)_{f} \alpha}$

The online version of the original article can be found under doi:10.1007/s00231-011-0892-7.

N. S. Akbar $(\bowtie) \cdot$ S. Nadeem · T. Hayat Department of Mathematics,

Quaid-i-Azam University 45320,

Islamabad 44000, Pakistan

e-mail: noreensher@yahoo.com

T. Hayat · A. A. Hendi

Department of Physics, Faculty of Science,

King Saud University, P.O. Box 1846,

Riyadh 11321, Saudi Arabia 